\title{
GOBERNANZA DE LAS EMPRESAS DOMINANTES EN LA CADENA DE CAFÉ: EL CASO DE LA REGIÓN DE TURRIALBA, COSTA RICA ${ }^{1}$
}

\section{GOVERNANCE OF DOMINANT COMPANIES IN THE AGRO COFFEE CHAIN: THE CASE OF THE REGION TURRIALBA, COSTA RICA}

\author{
Rosa Elena Cordero Peñaranda \\ Escuela de Economía, Universidad Nacional, Costa Rica, rocp15@hotmail.com
}

\author{
Jorge Andrey Valenciano Salazar \\ Escuela de Economía, Universidad Nacional, Costa Rica, Jorge.valenciano.salazar@una.cr
}

Recibido: 10 de setiembre, 2015 Aceptado: 24 de noviembre, 2015

\begin{abstract}
Resumen: El artículo analiza la gobernanza que se ejerce por parte de los actores que componen la cadena de café en la región de Turrialba, Costa Rica. La gobernanza se ejerce de diferentes maneras entre los distintos actores que componen la cadena, como por ejemplo: el beneficiador ejerce poder sobre los caficultores, puesto que establece las condiciones de calidad e inocuidad que debe tener el café entregado. La estructura de poder más estricta es ejercida por las empresas torrefactoras transnacionales, las cuales determinan los parámetros de calidad del café para su respectiva comercialización y en la mayoría de los casos determinan los precios que se pagan por el café.
\end{abstract}

Palabras clave: Cadenas de valor, gobernanza, café, Turrialba

\begin{abstract}
The governance conducted by the parties involved in the coffee chain in the region of Turrialba, Costa Rica, is analyzed in this paper. Governance is exercised differently by the various parties in the chain. For instance, coffee mills exercise power over farmers given that the former establishes coffee quality and safety conditions. The most rigid power structure is from transnational roasting companies, which set coffee quality standards for marketing and, in most cases, set coffee prices.
\end{abstract}

Keywords: Value chains, governance, coffee, Turrialba

Artículo realizado dentro del proyecto de investigación "Análisis de los determinantes de la sostenibilidad de la agricultura familiar en los cantones rurales de Costa Rica" de la Escuela de Economía de la Universidad Nacional. 


\section{Introducción}

Este artículo muestra la estructura y gobernanza de la cadena de café para el caso de Turrialba en Costa Rica, para realizar dicho estudio se trabajó con información tanto primaria como secundaria. En el caso de la información primaria se entrevistaron 10 pequeños caficultores y dos grandes productores de café, los cuales a su vez son beneficiadores; además, se realizaron entrevistas a cuatro miembros de instituciones públicas que afectan al sector cafetalero (dos del Ministerio de Agricultura y Ganadería y dos del Instituto Costarricense del Café2).

El análisis de la gobernanza toma relevancia debido a que identifica el actor que posee el poder en la cadena de valor, en este caso, se busca determinar el agente económico que ejerce este poder en la cadena de la producción de café en el cantón de Turrialba. Para tal efecto se distinguen dos análisis: el primero es el de la gobernanza entre eslabones de la cadena (gobernanza más específica en la cadena), que reviste importancia debido a lo siguiente:

(...) aunque todas las cadenas inician por los productores y terminan en los consumidores finales, en el proceso se presentan relaciones económicas entre los eslabones que determinan la gobernanza de la cadena, además que pocas veces se presentan de acuerdo al comportamiento de un mercado competitivo donde el precio se determina por la oferta y la demanda. En este tipo de cadena, la calidad, el origen, el cuidado del entorno y medio ambiente, la responsabilidad social con productores y trabajadores en términos de pago justo y calidad de vida de los mismos, juegan un papel tan importante, o más, que el precio (Velásquez, Marisol, s.f.,p.1).

El segundo análisis es el de la gobernanza orientada por los productores o compradores (gobernanza general de la cadena). En este caso, la cadena de café está orientada por los compradores, es decir, el poder no se ejerce solamente entre los actores de un eslabón sobre los actores de otro eslabón (por ejemplo beneficios que ejercen poder sobre los caficultores), sino que existe un agente que domina la cadena en términos globales, en el caso del café son los torrefactores los que determinan las condiciones globales de la cadena, es por ello se dice que es una cadena orientada desde la demanda.

\section{Características sociales de la región de Turrialba}

Según el Censo de Población y Vivienda 2011, Turrialba cuenta con una población de 69.616 personas en una extensión de 1.642,6 $\mathrm{Km}^{2}$ y, por tanto, tiene una densidad de población de

$2 \quad$ Ver en Anexo 1 las personas entrevistadas. 
42,4 habitantes por kilómetro cuadrado. De su población total, el 57 \% viven en zona urbana y el $43 \%$ en zona rural (INEC, 2011).

Según los indicadores educativos, el porcentaje de población que asiste a educación regular ${ }^{3}$ es del 69,7\%. Mientras que de la población de 10 años y más, un 4 \% se encuentra en condición de analfabetismo, es decir, no sabe leer ni escribir. (Instituto Nacional de Estadisticas y Censos, 2011).

Desde el punto de vista del empleo en Turrialba, la tasa de desempleo abierto es menor al promedio a nivel nacional. Asimismo, a pesar de ser una región netamente agrícola, el sector primario no ocupa la primera posición en las labores que realiza la población ocupada, tal y como se muestra en el tabla1.

Tabla 1. Turrialba: Indicadores económicos y laborales 2011

\begin{tabular}{|c|c|c|c|}
\hline & Indicador & $\%$ nacional & $\begin{array}{c}\text { \% del cantón } \\
\text { (Turrialba) }\end{array}$ \\
\hline \multicolumn{2}{|c|}{ Población de 15 años y más } & 75,2 & 75,7 \\
\hline \multicolumn{2}{|c|}{ Tasa neta de participación } & 53,5 & 47,5 \\
\hline \multicolumn{2}{|c|}{ Tasa de ocupación } & 51,7 & 46,1 \\
\hline \multicolumn{2}{|c|}{ Tasa de desempleo abierto } & 3,4 & 3 \\
\hline \multicolumn{2}{|c|}{ Porcentaje de población económicamente inactiva } & 46,5 & 52,5 \\
\hline \multicolumn{2}{|c|}{ Relación de dependencia económica } & 148,7 & 178,3 \\
\hline \multirow{3}{*}{$\begin{array}{c}\text { Porcentaje } \\
\text { de población } \\
\text { ocupada }\end{array}$} & Sector Primario & 13,7 & 21,6 \\
\hline & Sector Secundario & 18 & 17,1 \\
\hline & Sector Terciario & 68,2 & 61,3 \\
\hline
\end{tabular}

Fuente: Instituto Nacional de Estadísticas y Censos, Censo 2011.

Además, según el Índice de Competitividad Cantonal publicado por el Observatorio de Desarrollo de la Universidad de Costa Rica (Ulate, Madrigal, Ortega, \& Jiménez, 2012), Turrialba pasó de ocupar la posición 48 en el año 2006 al puesto 45 en el año 2011. Sin embargo, esta mejora no se refleja en otras cifras, según el Censo 2011 realizado por el INEC, en Turrialba se ubican el 1,92 \% del total de hogares pobres del país. Al analizar individualmente la región, un $24,96 \%$ del total de hogares de la zona son pobres, es decir, 19.820 personas se mantienen en condición de pobreza. Dadas estas características, el cantón se ubica en un nivel medio

3 Se refiere a la relación porcentual entre la población que asiste a centros de enseñanza o de cuido, respecto al total de la población (Instituto Nacional de Estadisticas y Censos, 2011). 
de incidencia de la pobreza, con un nivel de brecha de pobreza ${ }^{4}$ de 8,63 , una severidad de la pobreza ${ }^{5}$ de 4,19 y un Coeficiente de Gini $^{6}$ de 46,58.

\section{Caracterización de Turrialba como región cafetalera}

El área cultivada de café a nivel nacional se ha reducido del año 2001 al 2012, especialmente en las regiones cafetaleras de Turrialba y Pérez Zeledón, con una contracción del 42,49 \% y 25,87 $\%$ respectivamente, tal como lo muestra la tabla 2.

Tabla 2. Costa Rica: Área nacional cultivada con café.

Datos en hectáreas, 2001 y 2012

\begin{tabular}{lrr}
\hline Región Cafetalera & \multicolumn{1}{c}{ Área 2001 } & Área 2012 \\
\hline Coto Brus & $11.633,26$ & $8.947,74$ \\
Los Santos & $24.381,39$ & $23.353,14$ \\
Pérez Zeledón & $18.645,29$ & $13.821,14$ \\
Turrialba & $11.911,76$ & $6.850,90$ \\
Valle Central & $18.198,04$ & $14.892,44$ \\
Valle Occidental & $25.476,30$ & $23.616,15$ \\
Zona Norte & $2.883,90$ & $2.292,70$ \\
Área Nacional & $113.129,94$ & $93.774,21$ \\
\hline
\end{tabular}

Fuente: CATIE e ICAFE (2012) citado por Instituto del Café de Costa Rica.

Los pequeños productores de café de la zona de Turrialba alegan que la disminución de la producción se debe a los bajos precios del café, por lo que han tenido que vender sus tierras o en algunos casos, cambiar el uso del suelo para el cultivo de otros productos que les resulten más rentables; lo que ha provocado el cierre de beneficios o cooperativas de gran importancia para la zona. Sumado a esto, es de gran relevancia para el análisis, mencionar que los sectores servicios y comercio han venido a suplantar al menos en generación de empleo, a la agricultura, lo que coincide con la tendencia exhibida a nivel nacional. La llegada de empresas importantes como Rawlings y Firestone son ejemplos claros que muestran esta tendencia en la región.

\footnotetext{
$4 \quad$ También conocido como intensidad de la pobreza, muestra de manera relativa cuánto se aleja el ingreso promedio de los hogares pobres respecto a la línea de pobreza, cuando el indicador crece se describe un incremento en la intensidad de la pobreza, es decir un alejamiento del ingreso promedio de los hogares respecto a la Línea de Pobreza.

5 Refleja la desigualdad de ingresos existente entre los hogares pobres, es análogo a la brecha de pobreza, sin embargo es más sensible al cambio en el ingreso de los hogares con ingresos más bajos. Cuando el indicador aumenta se dice que la pobreza es más severa.

6 Mide el grado de concentración del ingreso, el cual varía entre cero y uno, entre más cercano de cero se encuentre significa que hay una igualdad en la distribución del ingreso, mientras más cercano a uno hay una mayor desigualdad en el ingreso.
} 
La Región Cafetalera de Turrialba está conformada por los cantones de Alvarado, Jiménez, Cartago, Paraíso, Siquirres y Turrialba. Sin embargo, si se toma solamente al cantón de Turrialba este contaba para el 2012 con 3.772 hectáreas de café, según la tabla 3, donde destaca la participación de los distritos de Turrialba, Santa Rosa y Santa Teresita.

Tabla 3. Turrialba: Área cafetalera según distrito. En hectáreas. 2012

\begin{tabular}{ccc}
\hline Cantón Turrialba & Distrito & Área Cafetalera 2012 (has) \\
\hline Chirripó & 43,70 \\
La Isabel & 147,90 \\
La Suiza & 389,00 \\
Pavones & 365,30 \\
Peralta & 12,40 \\
Santa Cruz & 59,00 \\
Santa Rosa & 827,00 \\
Santa Teresita & 696,30 \\
Tayutic & 138,00 \\
Tres Equis & 41,40 \\
Tuis & 294,30 \\
Turrialba & 757,40 \\
Total & $\mathbf{3 . 7 7 2}$ \\
\hline
\end{tabular}

Fuente: Elaboración propia con base en estadísticas suministradas por ICAFE.

Las altitudes de sus tierras cafetaleras se encuentran entre los 600 y 1.400 metros; con una precipitación promedio anual de 2.600 milímetros y una temperatura promedio anual de $21,5^{\circ} \mathrm{C}$. En un área de 8.500 hectáreas se cultiva las variedades Caturra y Catuaí Rojo bajo sombra de árboles de leguminosas y especies maderables, en especial, el Laurel. Los suelos son de origen volcánicos y aluviales. Los suelos son de origen volcánicos y aluviales. (Instituto del Café de Costa Rica, s.f).

La cantidad de fanegas producidas en el cantón de Turrialba por año por hectárea ha disminuido notablemente; de la cosecha 2009-2010 a la cosecha 2013-2014 se redujo de 64.225 a 50.588 fanegas, lo que representa una tasa de decrecimiento de $21 \%$, que en términos de explotación agrícola hace referencia a las condiciones difíciles de producción y comercialización del producto a nivel local y en los mercados internacionales, además del efecto de la enfermedad de la roya que afectó fuertemente la producción de café del cantón a partir del año 2012. 
$120.000,0000$

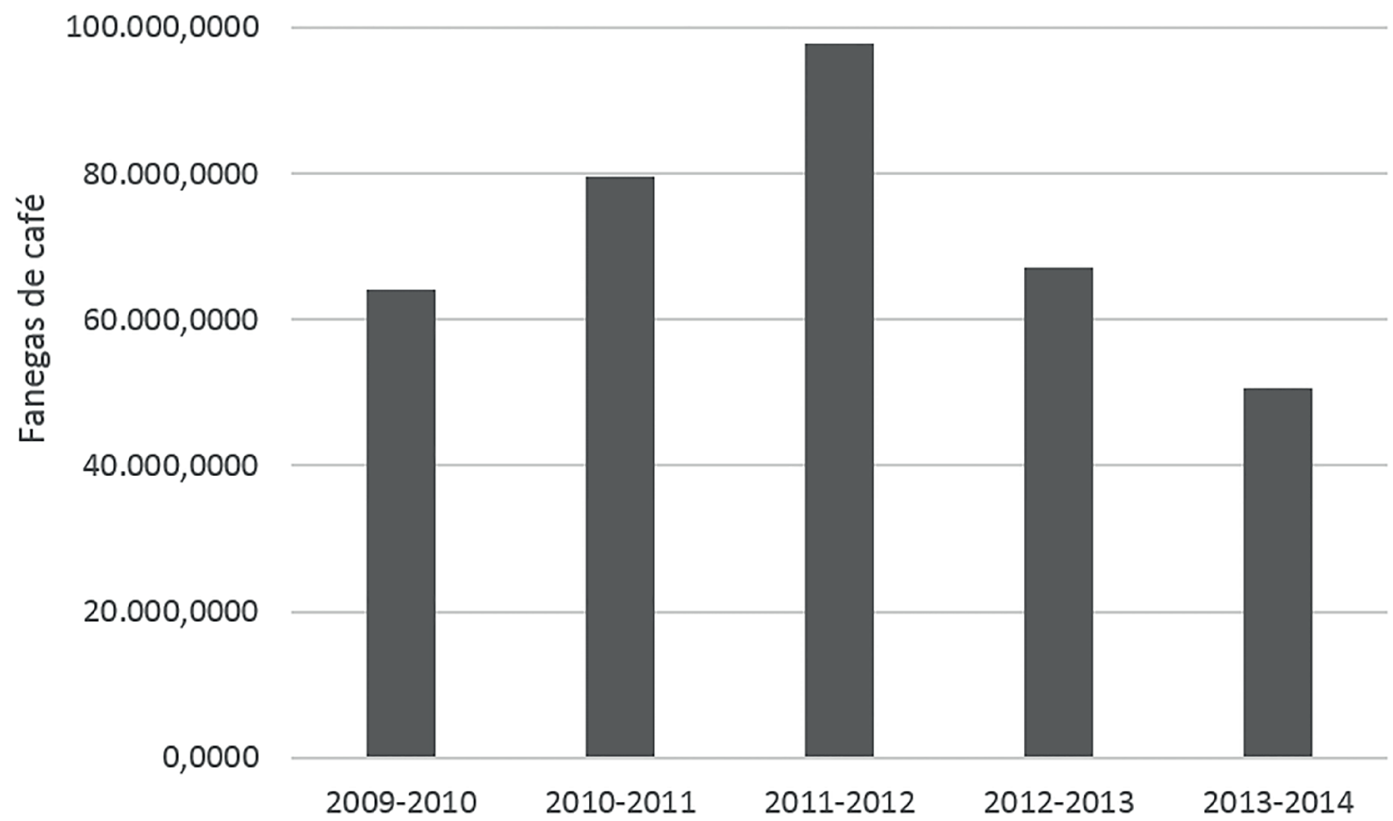

Figura 1. Cantón de Turrialba: Fanegas de producción. Cosecha 2009-2010 a 213-2014.

Fuente: Elaboración propia con base en ICAFE, 2013: Anexo 2.1.

\section{Estructura de insumo-producto de la agrocadena de café en Turrialba}

La estructura de la agrocadena de café en el cantón de Turrialba está conformada por un eslabón dedicado a la producción agrícola, el cual, según Martínez (2013) lo componen un total de 2.600 productores. El siguiente eslabón es el agroindustrial, conformado por los beneficiadores, los cuales comercializan una pequeña cantidad para el consumo local, y el $90 \%$ de lo que producen se exporta y comercializa a través de los grandes torrefactores internacionales, y algunas colocaciones directas hacia Europa y EE. UU., mediante la explotación de nichos de mercado específicos.

$7 \quad$ Una fanega equivale dos dobles hectolitros, aproximadamente 254 kilogramos de café cereza, esta tiene un rendimiento aproximado a un saco de 46 kilos de café oro, seco y listo para la exportación). 


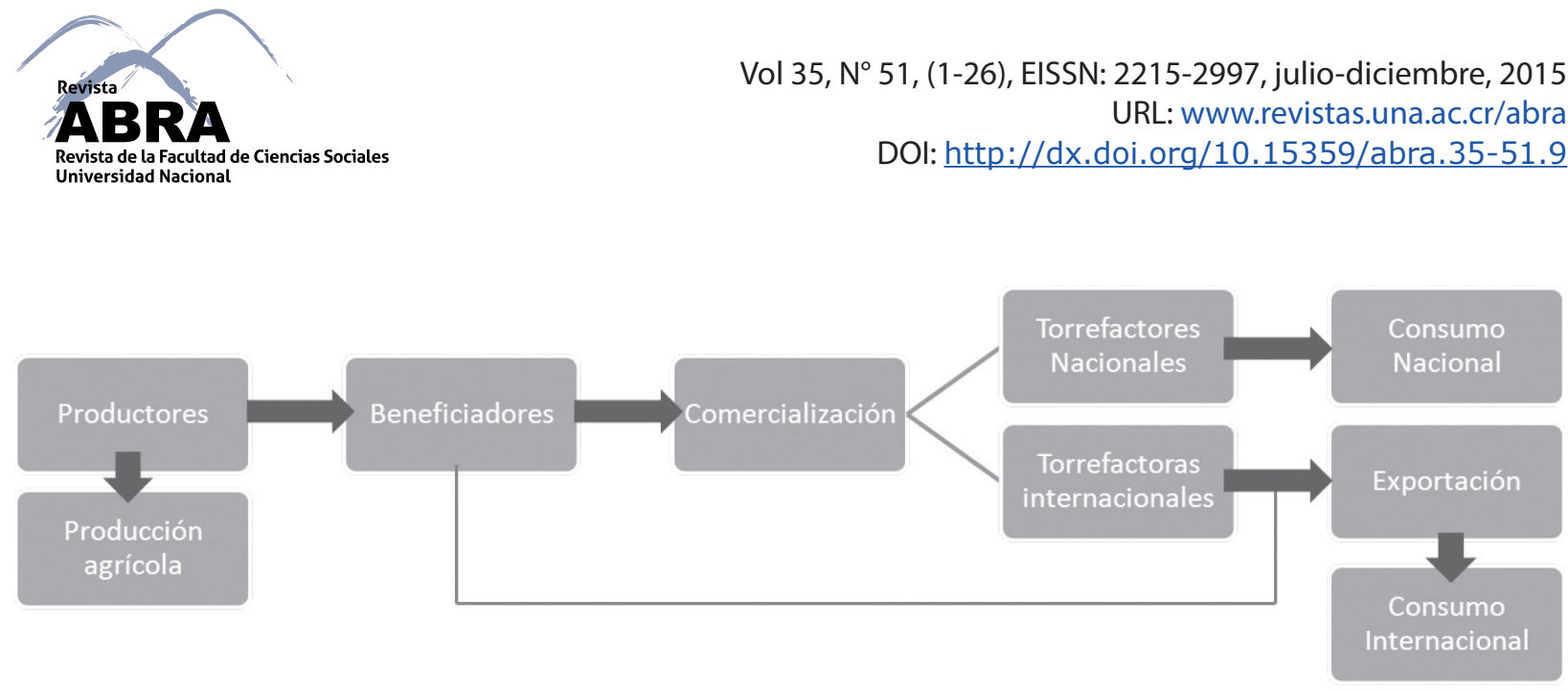

Figura 2. Turrialba: Agrocadena de valor de café.

Fuente: elaboración propia con datos recopilados en entrevistas realizadas.

\section{Producción y precios del café en la región de Turrialba}

Los caficultores de Turrialba, tienen un nivel de productividad promedio de 24,05 fanegas por hectárea según entrevista realizada al ingeniero del ICAFE, Adolfo Martínez en el año 2013. Tomando este dato de referencia, el costo de producir una fanega ${ }^{8}$, para los pequeños productores, es de aproximadamente 67.754,85 colones, según la estructura de costos del ICAFE para la cosecha 2012-2013 (Instituto del Café de Costa Rica , 2013), y el precio que recibieron por cada una fue de 79.166,58 colones para la cosecha 2011-2012, según el Informe de la Actividad Cafetalera 2012 (Instituto del Café de Costa Rica, 2012, p. 31); es decir, el margen de ganancia por fanega para los cafetaleros de Turrialba fue en promedio de 11.411,73 colones por fanega producida en el año 2012.

El precio de liquidación entre cosechas, (ver tabla 4), depende de la proporción de café por mercado de destino (exportación y consumo nacional), el rendimiento del beneficiado, el tipo de cambio al cual se vendieron los dólares recibidos producto de las exportaciones, así como los costos de operación del proceso de beneficiado (Instituto del Café de Costa Rica, 2012, p. 31).

Asimismo existe una importante diferencia de precios según las zonas cafetaleras del país, en la tabla 4 se observa que zonas de producción de café de altura, principalmente Valle Central, Valle Occidental y la Zona de los Santos tienen precios promedio de liquidación al productor aproximadamente un $17 \%$ mayor a la región de Turrialba, de hecho, la región de Turrialba tiene los segundos precios de liquidación más bajos de todo Costa Rica, solamente en la región de Pérez Zeledón se pagan precios menores al productor. Sin embargo, los productores del cantón de Turrialba deben hacer frente a altos costos de producción ligados a un clima muy húmedo que propicia la aparición de enfermedades como el ojo de gallo o la roya.

8 De modo general, estos costos por fanega incluyen: las labores de cultivos (poda, deshija, arreglo de sombra, resiembra y/o repoblación, fertilizaciones, entre otras), mano de obra, cargas sociales, transporte, costos administrativos, entre otros. 
Tabla 4. Precios de liquidación promedio. Por Región Cafetalera. En miles de colones por fanega. Cosechas 2009-2010 a 2011-2012.

\begin{tabular}{cccc}
\hline Región Cafetalera & \multicolumn{3}{c}{ Año Cosecha } \\
\hline & $2009-10$ & $2010-11$ & $2011-12$ \\
Coto Brus & $64.108,57$ & $72.220,09$ & $84.786,44$ \\
Los Santos & $68.740,92$ & $96.516,36$ & $92.116,75$ \\
Pérez Zeledón & $58.132,91$ & $72.815,19$ & $69.204,79$ \\
Turrialba & $59.380,30$ & $71.857,17$ & $79.166,58$ \\
Valle Central & $68.599,57$ & $100.130,90$ & $92.414,33$ \\
Valle Occidental & $72.369,75$ & $102.156,69$ & $92.276,75$ \\
Zona Norte & $68.675,33$ & $87.888,43$ & $89.657,82$ \\
Nacional & $67.006,00$ & $93.084,68$ & $87.547,86$ \\
\hline
\end{tabular}

Fuente: Instituto del Café de Costa Rica, 2012, pág. 31

Ahora bien, si se analiza la tendencia de los precios de liquidación al productor utilizando el promedio nacional, se observa como a partir de la cosecha 2001-2002 los precios mantuvieron una tendencia creciente hasta la cosecha 2009-2010, a partir del 2010-2011 los precios disminuyen y si bien se recuperan en la cosecha 2013-2014, todavía no se llega al pico máximo alcanzado en el punto de inflexión en el 2009. Esto hace que con unos costos de producción crecientes, las ganancias para el productor se vean reducidas en la actualidad.

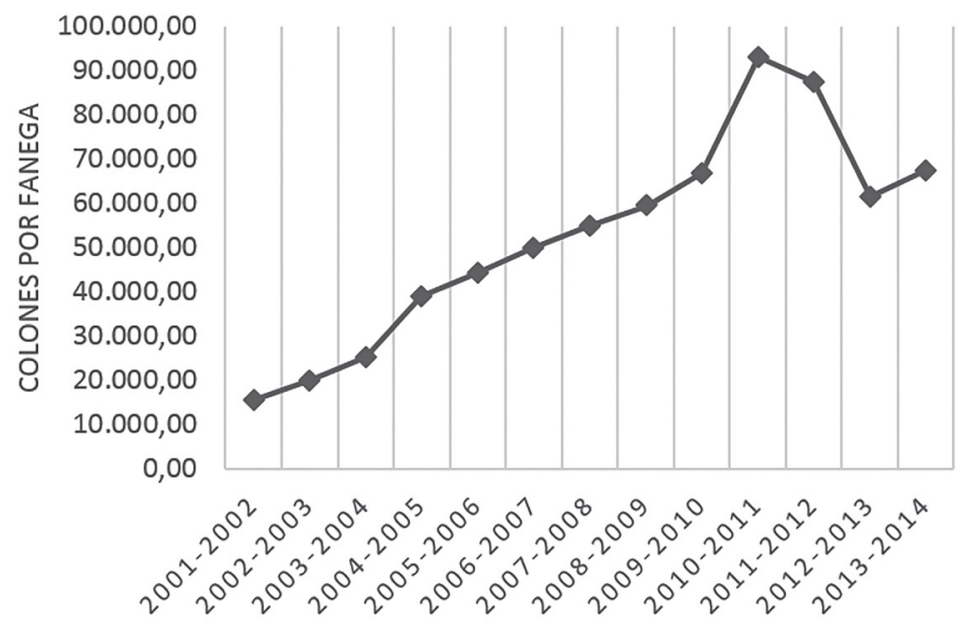

Figura 3. Costa Rica. Tendencia de los precios al productor. Liquidación promedio en colones 2001-2014.

Fuente: Elaboración propia con base en ICAFE, 2014: Anexo 2.3. 


\section{Características de los pequeños productores}

La caracterización de los pequeños productores se realizó con base en las entrevistas realizadas a las personas relacionadas con la cadena del café en Turrialba (ver anexo 1). En el cantón de Turrialba existe un historial de producción de café de más de 200 años lo que hace que la mayor parte de los pequeños productores desarrolle su actividad basado en su experiencia empírica.

Según ICAFE, los pequeños productores son aquellos que producen menos de 100 fanegas de café por año, para los datos agregados de Costa Rica en el año 2012, el 91,6\% de los productores tenían esa condición representando el $40,8 \%$ de la producción nacional total.

Los pequeños productores del cantón se caracterizan por tener una edad superior a los 45 años y por vivir en las zonas rurales, su núcleo familiar está conformado por dos hijos aproximadamente; en cuanto a su formación académica, los cafetaleros cursaron la primaria completa y en algunos casos, hasta la secundaria.

Estos productores tienen rendimientos promedio de 24 fanegas por hectárea y destinan una pequeña parte de la cosecha de café para el consumo familiar y la gran mayoría de su producción es vendida a las grandes empresas beneficiadoras, las cuales son privadas, ya que no existen beneficios cooperativos en la región.

Según el resultado de las entrevistas realizadas, cerca de un $69 \%$ de los pequeños productores de la zona entrega el café a la Compañía Santa Rosa, debido a las facilidades que esta les ofrece como por ejemplo: recogen el café en sus fincas, y es una empresa muy responsable en el pago del café, lo cual le da mucha credibilidad a los productores.

Los pequeños y medianos productores también son muy dependientes del crédito, al cual recurren constantemente para darle mantenimiento al cultivo mediante la compra de insumos, dichos créditos se pagan al final del año con la cosecha.

Durante el proceso de mantenimiento de las plantaciones, los pequeños productores no requieren contratar trabajadores, ellos mismos realizan el proceso, con excepción de la etapa de cosecha, momento en el que se requiere contratar temporalmente a algunas personas para que colaboren con la recolección.

\section{Algunas características de los grandes productores del cantón de Turrialba}

En la región existen al menos tres caficultores con grandes cantidades de hectáreas dedicadas al cultivo, lo que los caracteriza como grandes productores. Entre ellos se encuentra la Hacienda Juan Viñas. Este beneficio cuenta con 450 hectáreas cultivadas en la zona de Juan Viñas, parte 
de esas hectáreas se destinan al cultivo de caña de azúcar y macadamia. Esta hacienda posee la marca de café Juan Viñas Raíces así como el café Raíces, producido en cantidades limitadas bajo estrictos estándares de calidad definidos por la propia planta de la compañía. Se exporta café verde para tostadores seleccionados como Dallis Bros en los Estados Unidos y Europa. Estos tostadores luego venden el café tostado con el nombre de Juan Viñas en cafeterías especializadas y supermercados de estas latitudes. Además, otra conocida marca de café verde es el Juan Viñas Premium, este café regional mezcla granos de la Hacienda Juan Viñas y de más de 150 agricultores locales que procesan su café en el beneficio de esta hacienda. Ambos cafés se venden en cantidades limitadas a precios elevados (Hacienda Juan Viñas, 2012; Martínez, 2013).

Otro importante gran productor es la Cafetalera Aquiares, que nace en el año 1982 en Aquiares de Turrialba. Posee 917 hectáreas cultivadas, según datos proporcionados por Armando Jara (encargado de producción de la Cafetalera Aquiares), la producción promedio de café de los últimos años ha sido de 15.000 sacos de 69 kilos, de los cuales el 95 \% se exporta a Norteamérica, Europa y Japón y un $5 \%$ se vende localmente (a través de subastas entre los tostadores nacionales). Los principales compradores del café de esta cafetalera son las grandes empresas Café Capris de Volcafé (25\%), Ceca (10\%) y Cafinter (60\%), otros canales de comercialización (5\%) (Jara, 2012).

La Compañía Santa Rosa nace en el año 1969 y cuenta con 120 hectáreas cultivadas en Santa Rosa de Turrialba. El 90 \% de sus ventas son para exportación y el $10 \%$ restante para consumo nacional; siendo Café Capris su principal comprador de café procesado oro listo para la torrefacción, la cual absorbe el $75 \%$ de sus ventas totales, mientras que el restante $25 \%$ se destina a Ceca y a la exportación directa a una empresa en Italia (Assoviazione Caffe Speciali Certificati) la cual les exige que no haya intermediarios para exportación y que sus fincas sean certificadas (Cruz, 2012).

\section{Beneficiado en fruta}

Este eslabón de la cadena se caracteriza por estar concentrado en pocas manos y principalmente de capital privado. Existen aproximadamente 16 beneficios de café en toda la Región de Turrialba, entre los que se encuentran 6 empresas beneficiadoras que incluyen a los grandes caficultores con integración vertical como Aquiares, Juan Viñas y Santa Rosa que son los que concentran el mayor porcentaje de producción y compras a otros productores de la zona. Estas empresas venden su café a grandes torrefactoras, nacionales o transnacionales.

Los pequeños productores entregan su café principalmente al beneficio de Compañía Santa Rosa) y estos son los que se encargan de comercializar el producto (en su mayoría es café de exportación). Sin embargo, también hay presencia de algunos micro - beneficios. 


\section{Torrefactores como procesadores de producto terminado}

A continuación se caracteriza la comercialización para la torrefacción destinada para el consumo nacional y la torrefacción que se realiza para el consumo a nivel internacional.

\section{Torrefacción nacional}

Aproximadamente un $10 \%$ del café producido en Turrialba es vendido por los beneficios para su torrefacción a nivel nacional por empresas como Café Rey, Ceca con sus marcas El Yodito, Café Don Manuel y Café Kapiwo, y que además son los maquiladores de tres de las principales marcas a nivel nacional como son: Café Amigo, Café Económico y Café Fedecoop.

\section{Torrefacción internacional}

El $90 \%$ de la producción de Turrialba, es vendida por los beneficios a empresas torrefactoras transnacionales como: Cafinter, oficina costarricense de Ecom, Cafinter S.A., la cual abrió sus puertas en 1989 en Cartago. Café Capris de Volcafé, con una experiencia de 230 años, es uno de los principales comerciantes de café en el mundo; y por último, se encuentra CECA, la cual fue fundada en 1950 como una de las primeras operaciones de exportación de origen para Bernhard Rothfos, y posteriormente fue adquirida por Neumann Kaffee Gruppe en 1988.

Estas empresas son las que exportan el café para ser procesado para el consumo internacional; de esta manera, el café de Turrialba es colocado en mercados internacionales como: Estados Unidos, Europa; además, según información brindada por la sede regional del ICAFE en Turrialba (Araya, 2013), el café de esta región ha logrado llegar a nuevos nichos de mercado como los asiáticos.

Los eslabones de la agrocadena de valor de la producción de café en la región de Turrialba están conformados principalmente por productores y beneficiadores, mientras que para los otros dos eslabones (torrefacción y comercialización) lo que existen son vínculos comerciales, es decir, en el cantón no existe el proceso de torrefacción a gran escala, sino que el producto se traslada a otro lugar del país o fuera del país para realizar dicho proceso.

\section{La gobernaza en las cadenas de valor}

Algunos factores pueden explicar el tipo de gobernanza que se ejerce entre los agentes de una cadena de valor, que además pueden ser determinantes a la hora de hacer la clasificación de las cadenas, Gereffi, Humphrey y Sturgeon propusieron cuatro factores especificos para clasificar el tipo de gobierno en las cadenas, dichos factores son los siguientes (Gereffi, Humphrey, \& Sturgeon, 2005, p. 85): 
La complejidad de la transferencia de la información y el conocimiento, requerido para completar una transacción particular, especialmente en las especificaciones de procesos y productos.

El grado en que la información pueda codificarse y transmitirse, es decir, cómo se transmite eficientemente la información sin necesidad de inversiones por parte de los agentes de la cadena.

Las capacidades de los actuales y potenciales proveedores en relación con los requerimientos de las transacciones.

Grado de coordinación explícita y asimetría de poder: se refiere al nivel de claridad que exista en la coordinación en la cadena y a la desigualdad del poder de la misma.

Como se aprecia en la tabla 5, las cadenas de valor se pueden caracterizar por tener relaciones de igualdad hasta relaciones jerárquicas entre sus diferentes agentes, de acuerdo con el comportamiento y combinación de los factores propuestos anteriormente, se proponen cinco tipos específicos de gobernanza: mercado, modular, relacional, cautiva y jerárquica.

Tabla 5. Determinantes claves de la gobernanza en las cadenas globales de valor.

\begin{tabular}{|c|c|c|c|c|}
\hline $\begin{array}{c}\text { Tipo de } \\
\text { gobernanza }\end{array}$ & $\begin{array}{l}\text { Complejidad de las } \\
\text { transacciones }\end{array}$ & $\begin{array}{l}\text { Habilidad para } \\
\text { codificar las } \\
\text { transacciones }\end{array}$ & $\begin{array}{c}\text { Capacidades del } \\
\text { proveedor }\end{array}$ & $\begin{array}{c}\text { Grado de } \\
\text { coordinación } \\
\text { explícita y asimetría } \\
\text { de poder }\end{array}$ \\
\hline Mercado & Bajo & Alto & Alto & Bajo \\
\hline Modular & Alto & Alto & Alto & \\
\hline Relacional & Alto & Bajo & Alto & \\
\hline Cautiva & Alto & Alto & Bajo & \\
\hline Jerárquica & Alto & Bajo & Bajo & Alto \\
\hline
\end{tabular}

Fuente: Gereffi et al. (2005).

Estos tipos de gobernanza son analíticos, no empíricos, aunque, según sus autores, han sido derivados de observaciones empíricas. A continuación se explica en que consiste cada uno de estos tipos de gobernanza (Gereffi, Humphrey, \& Sturgeon, 2005, págs. 83-84; Sturgeon, 2009, págs. 118-119): 
Coordinación de mercado: acuerdos caracterizados por precios al contado o transacciones repetidas en las cuales los costos de cambiar los socios son bajos en ambas partes de la cadena. El comprador y el vendedor no necesitan cooperar en la definición del producto, bien porque este se encuentra estandarizado, o porque el proveedor posee suficiente capacidad para proporcionar un resultado satisfactorio. Las transacciones tienen un carácter marcadamente impersonal.

Cadenas de valor modulares: en estas redes industriales los proveedores fabrican productos sujetos a las especificaciones de los clientes, pero con plena autonomía en cuanto a la organización, las competencias y las tecnologías aplicadas. Este tipo de cadenas utilizan maquinaria genérica, de modo que no se encuentran atados a clientes concretos. Este tipo de cadenas son características, por ejemplo en la industria electrónica.

Cadenas de valor relacionales: cuando no resulta posible codificar todos los aspectos vinculados a las transacciones, surgen redes industriales caracterizadas por interacciones complejas entre compradores y vendedores, quienes mantienen relaciones de cooperación basadas en la reputación y la confianza mutua. Los distritos industriales italianos constituyen un ejemplo de este tipo de cadenas, que son también características, entre otras, de la industria automovilística.

Cadenas de valor cautivas: está presente en las relaciones en donde los pequeños proveedores dependen de uno o varios compradores que por lo general tienen mucho poder. Además, se da un alto control por parte de la empresa líder hacia los proveedores, en donde estos últimos deben de seguir las condiciones que son establecidas por estas empresas que ejercen el poder.

Cadenas de valor jerárquicas: el actor principal de la cadena son empresas trasnacionales, integrada verticalmente con vínculos de control respecto al resto de las empresas que participan en ella mediante relaciones de propiedad.

\section{Análisis del poder entre eslabones de la cadena (tipos de gobernanza específica)}

El comportamiento de la gobernanza en una agrocadena se explica por tres factores: (1) la complejidad de la transferencia de la información y el conocimiento, (2) el grado de extensión que las codificaciones de esta información pueda tener y (3) las capacidades y el potencial de los proveedores en relación con los requerimientos de cada transacción (Gereffi, Humphrey, \& Sturgeon, 2005). Estos factores son determinantes en el momento de realizar la clasificación de las cadenas, para conocer mejor la relación de los diferentes actores dentro de los eslabones.

Considerando estos factores se pueden clasificar los tipos de gobernanza que existen en el caso de la cadena de café en Turrialba tal y como se muestra a continuación: 


\section{Relación productor-beneficio}

Dentro de la gobernanza micro, entre el pequeño productor de café y el beneficiador, sobresalen las empresas beneficiadoras como las que concentran el mayor poder, ya que los caficultores dependen completamente de ellos para poder entregar su producción para evitar pérdidas, por lo que se ajustan a las condiciones que estos (los beneficios) les establezcan para sus entregas de café.

En el caso de los beneficios, el que concentra el poder según los productores, es el Beneficio Santa Rosa, que aunque no es el más grande en tamaño o producción, es el beneficio que capta mayor cantidad de productores; según información brindada por los ingenieros del ICAFE en la región de Turrialba, el Beneficio Santa Rosa recibe café de 1.800 productores de los 2.600 de la zona, es decir, un 69,23 \% respecto del total (Martínez, 2013; Araya, 2013). Además, en entrevistas aplicadas a 10 productores de la zona, estos plantearon que por sus características de cercanía con las fincas, así como por otras facilidades que brinda, es el beneficio preferido para entregar el café.

En esta relación caficultor - beneficiador de café, existen determinantes ${ }^{9}$ del tipo de gobernanza entre estos eslabones de la cadena. Para este caso específico, se puede concluir que se presenta una relación de gobernanza cautiva, esto se debe a que los pequeños productores dependen de uno o varios compradores, en este caso de los beneficios a quienes entregan su café. A pesar de que los beneficios tienen sus propias plantaciones, también establecen relaciones comerciales con los pequeños productores, los cuales deben de seguir las condiciones que son establecidas como por ejemplo, café de calidad (no verde, no fermentado, entre otros), en caso de no cumplir los parámetros establecidos por los beneficios los pequeños caficultores no podrían vender su café u obtendrían precios bajos.

Además, analizando el tipo de gobernanza cautiva según los factores que la determinan, se puede observar que tanto el nivel de complejidad de las transacciones como la habilidad para codificarlas es alto, debido a que los pequeños productores deben de comprender y a su vez, comprometerse a entregar un café con la calidad y otros estándares establecidos que garanticen a los beneficios que el producto adquirido es totalmente igual al que producen en sus propias fincas. Además, el nivel de capacidad y potencial del productor como proveedor es bajo, teniendo en cuenta la escala y volumen de producción, por lo que pueden cumplir los estándares de los beneficios pero no para competir con ellos en el eslabón de comercialización.

$9 \quad$ Entiéndase determinante como fijar los términos de algo. 
Tabla 6. Tipo de gobernanza relación productor-beneficiador

\begin{tabular}{cl} 
Tipo de control & Cautiva \\
Complejidad de las transacciones & Alto \\
\hline Habilidad para codificar las transacciones & Alto \\
\hline Capacidades del proveedor & Bajo \\
\hline
\end{tabular}

Fuente: Elaboración propia

\section{Relación beneficio-torrefactor/comercializador}

Los agentes que componen ambos eslabones mantienen una relación de poder marcada, los productores dependen de los beneficios, así como estos últimos, dependen de los exportadores y comercializadores para que el café que producen sea vendido no solo a nivel nacional, sino también en mercados internacionales. Estas empresas comercializadoras establecen las reglas que deben cumplir los beneficios para que su café sea comprado y procesado por ellos; y a su vez, los beneficios deben cumplir a cabalidad todas las indicaciones, ya que de lo contrario no podrán acceder a los mercados internacionales.

Mediante la colaboración de los beneficios de la zona se obtuvo información que muestra como las empresas torrefactoras determinan los requerimientos que los beneficios deben cumplir haciendo efectivo el poder que estas empresas tienen dentro de la cadena del valor del café. Algunos de estos determinantes son los siguientes:

Requerimientos institucionales: los beneficios deben cumplir con la legislación jurídica y ambiental nacional; dentro de los tramites más importantes están los siguientes: que haya un contrato inscrito ante el Instituto del Café de Costa Rica (regulador de la actividad cafetalera), que el beneficio sea una compañía reconocida en Costa Rica, contar con los permisos de funcionamiento ante el Ministerio de Salud, estar inscrito en el Ministerio de Hacienda como contribuyente, y satisfacer los requisitos fitosanitarios del país importador.

Calidad del producto: por lo general, antes y durante el proceso de comercialización, estas empresas solicitan que se envié una muestra del café de aproximadamente 750 gramos. Si deciden comprar un lote, por ejemplo de 275 sacos de $69 \mathrm{~kg}$ cada uno, también se debe enviar una muestra del lote ya preparado, esto para que corroboren que el café tiene la calidad de la muestra que se les envió inicialmente (Jara, 2012). Algunos compradores primero visitan las fincas, los beneficios y posteriormente toman la decisión de comprar o no el café. 
Transporte de mercancía: como generalmente se vende el producto en precios bajo la denominación Franco a Bordo (FOB por sus siglas en inglés), entregado en los puertos de Moín o Caldera, los compradores indican cuál naviera debe llevarles el café hasta el destino final.

Certificación: la mayoría de empresas solicitan que haya certificaciones que demuestren la forma como se produce el café, por ejemplo, el Beneficio Aquiares cuenta con la certificación de Rainforest Alliance, que establece que la empresa produce café en armonía con la naturaleza y que le da un trato justo a sus trabajadores. Juan Viñas por su parte, tiene certificado su café en Rainforest Alliance, Nespresso, Starbucks C.A.F.E Practices y UTZ. En el caso de Compañía Santa Rosa, cuenta con una certificación Caffé Speciali Certificat, la cual les exige cumplir con el requisito de ser exportadores directos. Los costos de estas certificaciones son asumidos por los beneficios de café y por los propios caficultores, con tal de poder acceder a los mercados internacionales por intermedio de los grandes comercializadores y torrefactores internacionales.

En el caso de la relación beneficiador-torrefactor/exportador se presenta un tipo de gobernanza de cadenas de valor cautivas, ya que los actores principales de la cadena son las empresas trasnacionales que compran el café de los beneficios para ser comercializados. Los agentes de la cadena de la zona dependen de estas empresas para poder acceder a los mercados internacionales; la escala de producción de los beneficios de la zona no les alcanza para poder competir con las grandes compañías torrefactoras internacionales, por lo que deben acceder a los mercados por intermedio de éstas.

En esta relación existe un alto nivel de complejidad de las transacciones, es decir, de transferencia de información y conocimiento, debido a que el proceso de logística es controlado por las compañías transnacionales, ya que cuentan con toda la maquinaria y conocimiento del proceso, sobre todo en las mezclas de cafés que realizan en los mercados estadounidense y europeo, por lo que los gustos de los consumidores ya están moldeados a este tipo de mezclas. Además, la inversión en este proceso es demasiado alta como para que una pequeña o mediana empresa la pueda asumir.

Las capacidades de los proveedores son bajas si los comparamos con la gran oferta mundial que existe de café, tanto en volumen como en variedad. Las empresas torrefactoras poseen gran influencia en las economías rurales, ejercida por su alta demanda de café oro.

Tabla 7. Tipo de gobernanza relación beneficiador-exportador/comercializador.

\begin{tabular}{cl}
\hline Tipo de control & Cautiva \\
\hline Complejidad de las transacciones & Alto \\
\hline Habilidad para codificar las transacciones & Bajo \\
\hline Capacidades del proveedor & Bajo \\
\hline
\end{tabular}

Fuente: Elaboración propia 


\section{Análisis de la gobernanza general en la cadena de café de Turrialba}

Si se analiza la gobernanza desde el punto de vista general, los beneficios no son los que tienen el mayor poder, sino que este lo ejercen las empresas transnacionales y las empresas exportadoras, a quienes los beneficios les venden el café, es decir, la gobernanza está orientada por los compradores.

La gobernanza es dirigida por las grandes empresas torrefactoras y comercializadoras que son las que determinan las reglas, condiciones y especificaciones del producto. Los restantes agentes de la cadena deben ajustar sus prácticas productivas adaptadas a las condiciones de los torrefactores para que su café sea vendido en otras partes del mundo.

A continuación, se mencionan algunas de las empresas transnacionales que ejercen el poder en la relación beneficio-torrefactor y comercializador en la cadena, con influencia en la región de Turrialba:

Ecom Agroindustrial Corp: ECOM Agroindustrial Corp. Ltd. es una compañía de comercio de productos básicos y de procesamiento de productos básicos a nivel mundial, se centra en el café, el algodón y el cacao, con operaciones agrícolas auxiliares en las semillas oleaginosas y el mercado de carnes porcinas. ECOM es una de las tres principales comerciantes de café, uno de los más grandes torrefactores de café en el mundo, y entre los cinco principales comerciantes de algodón y cacao. La facturación de la empresa en 2011 fue de más de USD 4 mil millones y en ese año maneja aproximadamente 11 millones de sacos de café, 2 millones de pacas de algodón y 250.000 toneladas de cacao, por lo que es un participante de primer nivel en cada uno de sus negocios principales (Ecom Agroindustrial Corp, s.f).

Capris de Volcafe: es una de las principales compañías comercializadoras de café en el mundo. Producen, compran y transforman cafés de tipo Arábica y cafés Robusta, así como la producción y suministro de cafés gourmet de varios orígenes. La casa matriz se encuentra en Winterthur, Suiza. Volcafe mantiene operaciones en 14 países (ED\&F Man Holdings Limited, s.f).

Ceca: desde sus inicios ha estado involucrada en la compra de café directamente a los productores. Cuenta además con instalaciones para la transformación del café en diversos beneficios húmedos, y exportan principalmente a Estados Unidos, Europa y Japón (Ceca, 2013).

\section{Análisis de la gobernanza mediante agentes externos}

Los parámetros de producto y proceso también pueden ser establecidos por agentes externos a la cadena, tales como las entidades de gobierno y las organizaciones internacionales que regulan el diseño y la fabricación del producto, además velan por la seguridad del consumidor y definen reglas, entre otros. 
En el caso de las entidades de gobierno, se destacan: el Instituto del Café de Costa Rica, el Ministerio de Agricultura y Ganadería, el Servicio Fitosanitario del Estado, entre otras; las cuales se encargan de establecer las condiciones y reglas que deben cumplir las empresas cafetaleras para poder producir café según los estándares establecidos tanto en el país como en los mercados internacionales. A nivel internacional se deben cumplir los principios planteados dentro del Análisis de Peligros y Puntos Críticos de Control (APPCC o HACCP, por sus siglas en inglés) adoptados por la Comisión del Codex Alimentarius (CCA).

Otras organizaciones internacionales, como las empresas certificadoras de productos, regulan el diseño y la fabricación del producto y, además, definen las reglas de como producir en armonía con el ambiente, condiciones laborales, entre otra normativa.

Para analizar la influencia de los agentes externos, el artículo se concentra en la caracterización de las empresas certificadoras como parte de la gobernanza.

\section{Empresas certificadoras como parte del mecanismo de control}

El motivo por el cual se considera relevante el papel que desempeñan las empresas certificadoras se basa en el poder que ejercen, como parte del control, debido a que establecen los requerimientos que deben de cumplir las empresas para poder contar con sus certificaciones.

\section{Empresas mundiales certificadoras de café}

A continuación se analizará cada una de las empresas con quienes las cafetaleras de Turrialba certifican su café para cumplir con las respectivas condiciones que estos les establecen, así como los cambios que estas han tenido que implementar para poder relacionarse con ellas; para lo cual, es importante mencionar que:

(...) en la actualidad en el mercado de cafés diferenciados existen cuatro tipos de certificación, estas son: certificación de tercera parte, privada, voluntaria y comercio justo. Entre las certificaciones más conocidas durante los últimos 20 años son la certificación de tercera parte (orgánica) y de comercio justo, pero en los últimos cinco años otros tipos de certificaciones han cobrado gran notoriedad por su rápida expansión en el mercado de cafés diferenciados como Rainforest, UTZ Certified y Starbucks C.A.F.E Practices. De acuerdo a los aspectos sociales, económicos y ambientales considerados en los esquemas de certificación anteriormente descritos, se resaltan tres grupos. El primero, conformado por el comercio justo cuyos criterios son más sociales que ambientales. El segundo grupo, compuesto por los nuevos esquemas de certificación cuyas guías y/o códigos de conducta engloban criterios sostenibles (económicos, sociales, ambientales). Finalmente, el tercer grupo conformado por los esquemas ambientales cuyos criterios considerados 
son estrictos en este aspecto y muestran una falta de orientación en aspectos sociales principalmente (López, 2008, p.21, págs. 21-22).

Certificación UTZ (Universal Time Zone): esta es la certificación que posee el Beneficio Grano de Oro S.A. Representa agricultura sostenible con mejores perspectivas para los agricultores, sus familias y nuestro planeta. Los agricultores aprenden mejores prácticas agrícolas, crean mejores condiciones laborales y pueden cuidar mejor de sus hijos(as) y de la naturaleza. De esa manera, UTZ hace una contribución positiva a gran escala: los agricultores obtienen mejores cosechas, un mejor ingreso y mejores perspectivas y además cuidan del medio ambiente y aseguran los recursos naturales de la tierra (UTZ Certified, 2015).

Para adquirir esta certificación se requiere que la empresa se apegue a ciertas condiciones, tales como poner en marcha las mejores prácticas y condiciones laborales, desarrollar la actividad en armonía con la naturaleza y con mejor cuidado para las próximas generaciones (UTZ Certified, 2015).

Certificación Rain Forest Alliance: es la certificación que posee Cafetalera Aquiares. La certificación Rain Forest Allenace ayuda a los finqueros a soportar los imprevisibles vaivenes del mercado global al brindarles la clave para mejorar el manejo de la finca, levantar su capacidad de negociación y el acceso a mercados premium. Al implementar el sistema de manejo sostenible de la finca, los agricultores pueden controlar los costos, ganar eficiencia y mejorar la calidad de los cultivos. El sello de certificación es una garantía de que el café es cultivado en fincas donde los bosques, los ríos, los suelos y la vida silvestre son protegidos; los trabajadores son tratados con respeto, reciben salarios dignos, están equipados apropiadamente y reciben acceso a la educación y a sistemas de salud (Rain Forest Alliance, 2015).

Certificación Starbucks: certificación que también posee Cafetalera Aquiares. Starbucks adquirió 167 millones de kilogramos de café en el 2009 en todo el mundo. El 81 \% de esa cantidad, a saber, 136 millones de kilogramos correspondió a proveedores aprobados conforme a las Prácticas Coffee and Farmer Equity (C.A.F.E.) (Starbucks Corporation, 2014).

Los determinantes necesarios para poder vender a Starbucks son las siguientes (Starbucks Corporation, 2014):

1. Adquirir una certificación de este tipo C.A.F.E o Comercio Justo

2. Todo el café debe cumplir las normas de gran calidad de Starbucks.

3. Es imprescindible la transparencia. Los proveedores deben presentar pruebas de los pagos efectuados a lo largo de toda la cadena de suministro para garantizar qué parte obtiene el agricultor del precio que Starbucks paga por el café verde (sin tostar). 
4. Medidas aplicadas respecto a condiciones de trabajo seguras, justas y humanas. Incluyen la protección de los derechos de los trabajadores y condiciones de vida adecuadas.

5. Liderazgo medioambiental (evaluado por verificadores independientes).

6. Medidas aplicadas para gestionar los residuos, proteger la calidad del agua, ahorrar agua y energía, preservar la biodiversidad y reducir el uso de productos fitosanitarios.

Cafetalera Aquiares por ejemplo, ha tenido que aplicar un buen manejo de plagas y de los suelos, protección de nacientes de aguas de los ríos; en la parte social, un buen trato a las personas que laboran para ellos (salario justo, jornadas, salud ocupacional, charlas, capacitaciones, manejo de carga, entre otros).

Para dichos parámetros se tuvieron que realizar ciertos cambios como los espacios entre las casas y los cafetales, la existencia de un límite para evitar que lleguen residuos de agroquímicos, al igual que en los ríos, y además, implementar equipos de salud ocupacional como uniformes, equipos de protección buscando que el trabajador no lleve a su casa ropa contaminada, entre otros.

\section{Certificación CSC Qualified Product (Caffè Speciali Certificati, Asociación Italiana de Cafés especiales): certificación que posee la Compañía Santa Rosa.}

Esta certificación de Italia realiza mezclas comercializadas por sus miembros, mediante la realización de controles desde la plantación hasta la taza. Para ello se ponen en marcha una serie de procedimientos desarrollado solo para conseguir un nivel de calidad y demostrable. La participación de todas las etapas del ciclo de producción de café, a partir de la identificación de las plantaciones debe cumplir con los requisitos específicos de los controles en los tostadores individuales (Caffè Speciali Certificati, 2011).

Ahora bien, el común denominador de todas las empresas certificadoras es el costo de certificarse. El proceso de certificación es costoso por lo que para un pequeño productor resulta difícil realizar la inversión, por este motivo son, en la mayoría de los casos, los beneficios, quienes se certifican para poder comercializar el café en mercados internacionales. Los beneficios a su vez, exigen a los pequeños productores con el cumplimiento de ciertos parámetros para poder comprarles el café.

\section{Parámetros que establecen la gobernanza}

Para que exista gobernanza se deben establecer parámetros que permitan a los más poderosos de la cadena, influir en los demás agentes; si se analizan estos parámetros para la cadena de valor de la producción cafetalera de Turrialba se obtienen los siguientes resultados:

Acceso al mercado: como se mencionó anteriormente, los pequeños productores de la zona no tienen relación directa con los mercados internacionales debido a que son los beneficios los 
que tienen acceso a través de las grandes empresas transnacionales existentes en el sector. Por esta razón, los beneficios de la zona necesitan acceder a estas empresas para así poder conocer sus requisitos y producir conforme a sus condiciones y a su vez, realizar las demandas necesarias a los pequeños productores quienes les entregan su café.

Adquisición de capacidad de producción: en este caso, los beneficios que también son productores, al tener acceso a las empresas que son líderes en la cadena pueden aprender de lo que hacen las empresas comercializadoras y así adoptar mejores prácticas, consejos, recomendaciones, entre otras lecciones; y de esta manera, pueden aumentar sus capacidades de producción.

Distribución de las ganancias: es de gran importancia que cada uno de los actores de la cadena de café de Turrialba logren comprender cómo está gobernada la cadena, ya que de esta manera contarán con información valiosa sobre las funciones que debe asumir cada uno y de ser posible, establecer relaciones que le permitan desarrollar competencias, asumir responsabilidades y así, lograr una mejor distribución de las ganancias.

Puntos de apalancamiento para iniciativas políticas: permite ofrecer nuevos puntos de apalancamiento para nuevas iniciativas de gobierno, es decir, tratar de encontrar un punto en donde un pequeño cambio puede significar mejoras significativas y duraderas (un pequeño cambio puede llevar a un gran cambio en el comportamiento de toda la estructura de la cadena).

Orientación de la asistencia técnica: las empresas gobernantes en la cadena, en este caso las empresas transnacionales que son las encargadas de comercializar el café, orientan las tecnologías y procesos necesarios para aumentar o mejorar la calidad del café que viene desde de los productores y beneficiadores, para ser comercializado en mercados internacionales.

\section{Ejemplos de parámetros impuestos por las empresas o por agentes externos dentro de la cadena}

La razón principal para especificar los parámetros de proceso a lo largo de la cadena, es el riesgo (Humphrey \& Schmitz, s. f.). Dichos parámetros pueden ser impuestos por las empresas o por agentes externos como instituciones gubernamentales. A continuación se presentan algunos ejemplos de parámetros exigidos desde la empresa líder o agentes externos. 
Tabla 8. Ejemplos de parámetros impuestos en la cadena de café

Empresa líder

(1) Especificación de los controles de calidad impuestos desde los beneficios para poder recibir el café de los productores, tales como: no entregar café verde ni fermentado, características de finca adecuadas para cumplir con certificaciones.

(2) Controles de calidad desde los torrefactores a los beneficios (acidez, cuerpo, etc). Los torrefactores exigen que los beneficios cumplan con certificaciones internacionales.

(4) El gobierno establece que no se contrate mano de obra infantil, (5) el ICAFE establece un precio por fanega, (6) precios mínimos por recolección de café, entre otros.

Sin embargo, las empresas líderes son los responsables de cumplir con estas reglas.
Agentes externos

(3) Tal es el caso de las empresas transnacionales que solicitan a los beneficios estar inscritos en el ICAFE para poder negociar; el gobierno como agente externo, se encarga de velar de que verdaderamente los beneficios estén inscritos antes de asignar los permisos, entre otros.

(5) El gobierno establece que las exportaciones en general, en este caso las de café, sean monitoreadas de tal manera que si cumplen con los parámetros establecidos el producto podrá salir del país.

Fuente: Elaboración propia con base en (Humphrey \& Schmitz, sf).

\section{Conclusiones finales}

a. Los caficultores del cantón se caracterizan por su nivel de organización. No cuentan con asociaciones ni cooperativas que les permita luchar por obtener mejores ganancias de su producción, ya que los productores se convierten en tomadores de precios que estipulan los grandes beneficios de la zona, esto tiene implicaciones sobre los precios de liquidación, pero también sobre otras condiciones que ofrecería una cooperativa si existiera, como el crédito, la asistencia técnica, el poder de negociación, entre otros. Ante este panorama, la organización de pequeños productores es un paso primordial para que estos logren obtener mayores beneficios económicos y sociales en las actividades productivas y/o comerciales que realizan.

b. Alto grado de concentración en el eslabón de beneficiado. El sector de beneficiado en la región está concentrado en pocas empresas de capital privado, los cuales compiten según las facilidades que les brinden a los productores para que estos elijan procesar su café con ellos, por ejemplo: por precio de fanega, servicio de transporte desde sus fincas hasta el beneficio, pagos por adelantado, entre otros. Los principales beneficios que existen en la zona son Beneficio Santa Rosa, Beneficio Juan Viñas y Beneficio Aquiares; este último no recibe café de productores de la zona, sino que procesa únicamente el café de sus fincas. 
c. La gobernanza general de la cadena es ejercida por los compradores; el poder en la cadena de valor de la producción de café de este cantón, está en manos de los torrefactores/exportadores del café, los cuales son los que tienen acceso directo a los mercados internacionales.

Todos los beneficiadores de la zona dependen de las empresas transnacionales para poder comercializar el café que producen. De esta manera, cada uno debe de apegarse a los lineamientos y cumplir con las recomendaciones de calidad que estas establecen. El poder de estas empresas se manifiesta en su influencia sobre los precios, presentación y estrategias.

Para los beneficios no es conveniente perder ningún clientes, ya que existe un pequeño número de compradores para todo el sector, por lo que es indispensable tener su lealtad. Además, las transnacionales compran en grandes cantidades por lo que los beneficiadores deben de procurar brindar la calidad que sus compradores desean.

d. La gobernanza específica de la relación productor-beneficiador es cautiva; debido a que el poder en la cadena es ejercido por los beneficios y los pequeños productores dependen de ellos para poder entregar su café, puesto que se rigen según sus indicaciones y especificaciones para que el café no sea rechazado.

e. La gobernanza específica de la relación beneficiador-exportador es jerárquica; existe este tipo de gobernanza, ya que el actor principal de la cadena es la empresa trasnacional que compra el café de los beneficios para ser comercializado, es decir, el poder está concentrado en pocas manos.

En la actualidad, las empresas transnacionales han logrado consolidar y ampliar su creciente dominio sobre el mundo. El avance de los procesos de globalización económica ha servido para construir un entramado político, económico, jurídico y cultural, a nivel global, del que las empresas transnacionales han resultado ser las principales beneficiarias.

Las grandes corporaciones continúan fortaleciendo su poder e influencia en nuestras sociedades gracias a sus renovadas estrategias corporativas y a la constante aplicación de nuevos modelos de negocio, característica que no poseen los beneficios de la zona, por lo que es difícil que alcancen ese nivel de poder, por lo que dependen de este tipo de empresas.

f. La certificación en el sector es un mecanismo para ejercer la gobernanza; la obtención de una certificación para el café que se produce, no es un mecanismo o estrategia de calidad para los pequeños productores en esta cadena, sino que solamente es utilizada por los beneficiadores de la zona, para incentivar a los productores a producir café de calidad. 
Mediante estas certificaciones las empresas beneficiadoras obtienen más acceso a las grandes empresas torrefactoras por la calidad de su café y a su vez a los grandes mercados internacionales, situación que no sucede con los pequeños productores.

\section{Bibliografía}

Araya, M. (2013). Jefe Regional ICAFE Turrialba. (R. Cordero, Entrevistador)

Caffè Speciali Certificati. (2011). Caffè Speciali Certificati. Recuperado el Julio de 25 de 2013, de http:// www.caffespeciali.it/

Ceca. (2013). Ceca. Recuperado el 2 de Agosto de 2013, de http://www.ceca.co.cr/

Cruz, J. (2012). Funcionamiento Compañía Santa Rosa. (R. Cordero, Entrevistador)

Ecom Agroindustrial Corp. (s.f). Ecom Agroindustrial Corp. Recuperado el 21 de octubre de 2015, de www.ecomtrading.com/en/about-ecom.html

ED\&F Man Holdings Limited. (s.f). ED\&FMan Holdings Limited. Recuperado el 21 de Julio de 2013, de http://volcafe.com

Gereffi, G., Humphrey, \& Sturgeon. (2005). The Governance of Global Value Chains.

Humphrey, J., \& Schmitz, H. (sf). Las empresas de los países en vías de desarrollo en la economía mundial:poder y mejora de las cadenas globales de valor. http://www.inti.gov.ar/pdf/aportes1.pdf: Instituto Nacional de Tecnología Industrial.

ICAFE. (2014). Informe de Actividad Cafetalera 2014. San José, Costa Rica. : Instituto de Café de Costa Rica.

INEC. (2011). Recuperado el 16 de Julio de 2013, de http://www.inec.go.cr/Web/Home/GeneradorPagina.aspx

Instituto del Café de Costa Rica . (2013). Costos de Producción Agrícola de Café Fruta. Cosecha 20122013. San José, Costa Rica. : ICAFE.

Instituto del Café de Costa Rica. (2012). Informe de Actividad Cafetalera, 2012. San José, Costa Rica: ICAFE.

Instituto del Café de Costa Rica. (s.f). ICAFE. Recuperado el 28 de 9 de 2015, de http://www.icafe. go.cr/nuestro-cafe/regiones-cafetaleras/turrialba/ 
Instituto Nacional de Estadisticas y Censos. (2011). Recuperado el 16 de Julio de 2013, de http:// www.inec.go.cr/Web/Home/GeneradorPagina.aspx

Jara, A. (2012). Encargado de Producción de la Cafetalera Aquiares. (R. Cordero, Entrevistador)

López, J. L. (30 de Mayo de 2008, p.21). Oportunidades y limitaciones para el posicionamiento de pequeños cafetaleros de Costa Rica y sus empresas asociativas en mercados de cafés diferenciados. Costa Rica: Tesis sometida a consideración de la Escuela de Posgrado. Programa de Educación para el Desarrollo y la Conservación del Centro Agronómico Tropical de Investigación y Enseñanza y como requisito para el grado de: MAGISTER SCIENTIAE.

Martínez, A. (2013). Función del ICAFE en la Región Turrialba. (R. Cordero-Peñaranda, Entrevistador)

Rain Forest Alliance. (2015). Rain Forest Alliance. Recuperado el 5 de Junio de 2015, de http://www. rainforest-alliance.org

Starbucks Corporation. (2014). Starbucks Corporation. Recuperado el 23 de 10 de 2015, de http:// www.starbucks.es/responsibility/sourcing/coffee

Sturgeon, T. (2009). From Commodity Chains to value chains: Interdisciplinary Theory Building an Age of Globalization, en Frontiers of Commodity chain Research. California : University Press.

Ulate, A., Madrigal, G., Ortega, R., \& Jiménez, E. (Agosto de 2012). Universidad de Costa Rica. Obtenido de Índice de Competitividad Cantonal Costa Rica 2006-2011: http://www.icc.odd.ucr.ac.cr/ docs/ICC-OdD-2012.pdf

UTZ Certified. (2015). UTZ Certified. Recuperado el 22 de 10 de 2015, de www.utzcertified.org

Velásquez, Marisol. (s.f.,p.1). Una propuesta metodológica para el estudio de las relaciones económicas de poder: el caso delas cadenas agroindustriales de café. México: FES Acatlán, UNAM.

Volcafe. (2012). Volcafe. Recuperado el 21 de Julio de 2013, de http://volcafe.com/ 
Anexo 1: Funcionarios públicos y productores consultados

\begin{tabular}{|c|c|c|}
\hline Persona consultada & Lugar de trabajo & Función que desempeña \\
\hline Adolfo Martínez & ICAFE & $\begin{array}{c}\text { Encargado Sede Regional ICAFE } \\
\text { Turrialba }\end{array}$ \\
\hline Annie López & MAG & $\begin{array}{c}\text { Jefe de Dirección Regional del MAG } \\
\text { Turrialba }\end{array}$ \\
\hline Manuel Gómez & MAG & $\begin{array}{c}\text { Extensionista de café y caña, MAG } \\
\text { Turrialba }\end{array}$ \\
\hline Marco Araya & ICAFE & $\begin{array}{l}\text { Jefe de la Unidad de Estudios } \\
\text { Económicos y Mercado (UEEM) }\end{array}$ \\
\hline Jose Cruz & Compañía Santa Rosa & Propietario \\
\hline Armando Jara & Cafetalera Aquiares & Encargado de producción \\
\hline Alexis Vega Brenes & Cimarrón, Santa Teresita & Pequeño productor \\
\hline Héctor Fonseca Quirós & Tayutic, Turrialba & Pequeño productor \\
\hline Wilbert Smith Soto & La Suiza, Turrialba & Pequeño productor \\
\hline Elizabeth Salas Brenes & Colorado, Turrialba & Pequeño productor \\
\hline Luis Gerardo Molina Aguilar & Colorado, Turrialba & Pequeño productor \\
\hline Juan Solano Ulloa & Colorado, Turrialba & Pequeño productor \\
\hline Ramón Fernández Vargas & Santo Domingo, Colorado & Pequeño productor \\
\hline Juan José Solís Fonseca & Santo Domingo, Colorado & Pequeño productor \\
\hline Manuel Solís Fonseca & Colorado, Turrialba & Pequeño productor \\
\hline José Luis Contreras Robles & Colorado, Turrialba & Pequeño productor \\
\hline
\end{tabular}

